\title{
Daily Oral Grepafloxacin vs. Twice Daily Oral Doxycycline in the Treatment of Chlamydia trachomatis Endocervical Infection
}

\author{
W.M. McCormack, ${ }^{1 *}$ D.H. Martin, ${ }^{2}$ E.W. Hook III, ${ }^{3}$ and R.B. Jones ${ }^{4}$ \\ ${ }^{1}$ SUNY Health Science Center at Brooklyn, Brooklyn, NY \\ ${ }^{2}$ Louisiana State University and the Delgado Clinic, New Orleans, LA \\ ${ }^{3}$ University of Alabama at Birmingham, Birmingham, $A L$ \\ ${ }^{4}$ Indiana University School of Medicine, Indianapolis, IN
}

\begin{abstract}
Objective: To compare the efficacy and safety of a 7-day course of treatment with oral grepafloxacin, $400 \mathrm{mg}$ once daily, and oral doxycycline, $100 \mathrm{mg}$ twice daily, in patients with chlamydial cervicitis.

Methods: Women aged 18 years or older attending 17 sexually transmitted disease clinics in the United States who had clinical signs of mucopurulent cervicitis or who had a recent positive culture or nonculture test for Chlamydia trachomatis or who had contact with a male partner with a positive culture for $C$. trachomatis were enrolled into this randomized, double-blind, active-controlled clinical study. The diagnosis of chlamydial cervicitis was based on culture for C. trachomatis. Patients were randomized to receive a 7 -day course of treatment with either oral grepafloxacin, $400 \mathrm{mg}$ once daily, or oral doxycycline, $100 \mathrm{mg}$ twice daily. Response to therapy was assessed 3-8 days and 21-28 days after completion of treatment. The primary measure of efficacy was eradication of C. trachomatis at the 21-28 day follow-up visit. Clinical success, defined as improvement or complete resolution of the signs and symptoms of cervicitis, was a secondary measure of efficacy.

Results: Of the 451 female patients enrolled, 228 received grepafloxacin and 223 received doxycycline. In all, 154/451 (35\%) patients were evaluable at the 21-28 day follow-up (81 who received grepafloxacin and 73 who received doxycycline). Microbiologic and clinical success rates demonstrated the equivalence of the two treatments. The $C$. trachomatis eradication rates were $96.3 \%$ (78/81) and $98.6 \%$ (72/73) for patients receiving grepafloxacin or doxycycline, respectively. The two study drugs were also equivalent in resolving clinical signs and symptoms, with clinical success rates of $88.9 \%(64 / 72)$ and $89.5 \%(51 / 57)$ for patients treated with grepafloxacin and doxycycline, respectively. Both drugs were well tolerated, with $47 \%$ of patients receiving grepafloxacin and $46 \%$ of patients receiving doxycycline experiencing drug-related adverse events, none of which was serious.

Conclusions: Seven days of treatment with oral grepafloxacin, $400 \mathrm{mg}$ once daily, was as effective as 7 days of treatment with oral doxycycline, $100 \mathrm{mg}$ twice daily, in patients with cervicitis caused by $C$. trachomatis. Both agents were well tolerated and had comparable safety profiles. Grepafloxacin's once-daily dosing regimen may offer advantages in terms of patient compliance. Infect. Dis. Obstet. Gynecol. 6:109-115, 1998. @ 1998 Wiley-Liss, Inc.
\end{abstract}

Grant Sponsor: Otsuka America Pharmaceutical, Inc.

*Correspondence to: Dr. William M. McCormack, SUNY Health Science Center at Brooklyn, Box 56, 450 Clarkson Avenue, Brooklyn, NY 11203. 
$c$ lamydia trachomatis is the sexually-transmitted bacterial pathogen with the highest incidence in the United States, causing an estimated 4 million infections each year. ${ }^{1}$ Around 2.6 million infections occur in women and 1.8 million in men; 250,000 of these infections occur in infants. ${ }^{2} \mathrm{Up}$ to $75 \%$ of women with uncomplicated chlamydial infection are asymptomatic, ${ }^{3}$ making the actual number of infected individuals difficult to determine. In some infected women, yellow or green mucopus is apparent in the endocervical canal. There may also be areas of edematous and friable cervical ectopy that bleed when manipulated. Urethral infection may also occur and, though usually asymptomatic, can be associated with dysuria and urinary frequency. $^{4}$

Infection with $C$. trachomatis causes considerable morbidity, particularly in women and their offspring. Chlamydial infection may cause minimal discomfort initially, allowing it to remain undetected. C. trachomatis first infects the cervix and may spread canalicularly to the endometrium, causing endometritis. Serious damage may occur when the organism ascends to the fallopian tubes, where it may manifest as acute salpingitis, an important cause of female infertility. ${ }^{5}$ Chlamydial infection has also been linked to ectopic pregnancy. Maternal carriage of $C$. trachomatis is associated with a high incidence of illness in the offspring, including pneumonia and inclusion conjunctivitis. ${ }^{6,7}$ Left untreated, infected infants may harbor $C$. trachomatis for 1-3 years, particularly in the nasopharynx, genital tract, or rectum. ${ }^{8}$

Preferred agents for the treatment of chlamydial infection are oral doxycycline, $100 \mathrm{mg}$ twice daily, for 7 days or a single 1-g dose of oral azithromycin. Noncompliance with multiple-dose regimens may be a particular problem in asymptomatic individuals, resulting in treatment failure and thus persistent infection and reinfection of sexual partners.

Grepafloxacin (previously called OPC-17116) is a new, orally administered fluoroquinolone with excellent in vitro activity against pathogens commonly associated with sexually transmitted diseases, including Neisseria gonorrhoeae, G. trachomatis and Ureaplasma urealyticum, ${ }^{9-11}$ which suggests that it may be an effective therapeutic option in sexually transmitted infections. Its activity in vitro against C. trachomatis $\left(\mathrm{MIC}_{90}=0.125 \mu \mathrm{g} / \mathrm{mL}\right)$ is superior to that of ofloxacin $\left(\mathrm{MIC}_{90}=2.0 \mu \mathrm{g} /\right.$
$\mathrm{mL}),{ }^{12,13}$ as is its elimination half-life (12 hours vs. 4 hours) (data on file), enabling it to be given as a single daily dose.

Serum and tissue concentrations attained with grepafloxacin also support its use in the treatment of genitourinary infection. Following oral administration, grepafloxacin concentrations in female genital tract tissues were higher than serum concentrations, with concentration ratios ranging from 2.1-5.2 for the endometrium, myometrium, cervix, portio vaginalis, ovary, and oviduct, indicating a high rate of penetration into these tissues. ${ }^{14} \mathrm{Grepa}-$ floxacin also accumulates in human polymorphonuclear leukocytes, suggesting that it may be useful in the treatment of infections caused by intracellular bacteria. ${ }^{15}$

The above microbiologic and pharmacologic profile, including potent activity in vitro against $C$. trachomatis, led to the initiation of this clinical study comparing grepafloxacin with doxycycline in women with chlamydial endocervical infections.

\section{SUBJECTS AND METHODS}

The patients studied were recruited at 17 public clinics for sexually transmitted diseases in the United States between November 1993 and August 1995. Patients eligible for enrollment in this randomized, double-blind, active-controlled investigation were nonpregnant women aged 18 years or over, practicing active contraception, who had signs of mucopurulent cervicitis based on mucopus within the endocervical canal or an endocervical Gram stain containing $\leq 10$ leukocytes per oil immersion field. Women were also enrolled if they had a recent positive culture or nonculture test for C. trachomatis for which they had not received treatment or if they had had contact with a male partner with a positive culture for $C$. trachomatis.

A medical history was taken at the pretreatment visit, and patients underwent a baseline physical examination and clinical laboratory tests. The first dose of antibiotic was given at this visit; patients were randomized to receive 7 days of treatment with either oral grepafloxacin, $400 \mathrm{mg}$ once daily, or oral doxycycline, $100 \mathrm{mg}$ twice daily. Patients were evaluated at follow-up visits 3-8 days and 21-28 days following completion of treatment. Patients were instructed to refrain from unprotected sexual contact until the 21-28 day posttreatment visit. The study was approved by the Institutional Re- 
view Board at each participating center, and written informed consent was obtained from all participants before enrollment.

\section{Exclusion Criteria}

Exclusion criteria included: pregnancy or lactation; women of childbearing potential not practicing acceptable contraception; a history of allergy to quinolone or tetracycline antibiotics; hospitalization for a non-study-related illness or procedure; treatment with antibiotics within 2 weeks prior to study entry; treatment with a concomitant antimicrobial agent other than topical antibiotic or antifungal agents; treatment with an investigational drug or device within 4 weeks prior to study entry; chronic treatment with warfarin, diflunisal, fluconazole, or theophylline; antacids or sucralfate taken within 4 hours of dosing; or a complicating infection, chronic disease or disorder that could interfere with study results, including active seizure disorders, hepatic or gastrointestinal disease, terminal illness or severe immunocompromised status, evidence of chronic, ascending, or disseminated genital infection, evidence of active herpes simplex virus infection, or a concurrent disease requiring immediate antibiotic treatment.

\section{Microbiologic Investigations}

At the pretreatment visit, an endocervical Gram stain was examined for leukocytes and intracellular gram-negative diplococci and vaginal cultures for cervical cultures for $N$. gonorrhoeae, $C$. trachomatis, U. urealyticum, and Mycoplasma hominis were examined with the use of the routine methods of each participating laboratory. Patients with a positive culture for $N$. gonorrhoeae were withdrawn and treated with an appropriate antibiotic. At the 3-8 day posttreatment visit, endocervical Gram stain and cervical cultures for $N$. gonorrhoeae and $C$. trachomatis were repeated. Patients with a positive culture for $N$. gonorrhoeae were withdrawn. Endocervical Gram stain and culture for $C$. trachomatis, $U$. urealyticum, and $M$. hominis were also obtained at the 21-28 day posttreatment visit.

Susceptibility testing against grepafloxacin and doxycycline was performed on every third isolate of C. trachomatis from each study center. McCoy cell monolayers were incubated in triplicate with the specimen and the appropriate concentration of antibiotic and plates incubated for 72 hours at $30^{\circ} \mathrm{C}$ in
$2 \% \mathrm{CO}_{2}$. Cells were then fixed and stained with fluorescent antibody. Positive cultures were defined as those showing $\geq 1$ characteristic fluorescent chlamydial intracytoplasmic inclusion and negative cultures as those having minimal or no nonspecific staining and no fluorescent chlamydial inclusions.

\section{Microbiologic Response}

The primary measure of study drug efficacy was microbiologic response to therapy. The microbiologic response was based on the eradication of $C$. trachomatis as judged by a comparison of pre- and posttreatment cultures. A patient with negative cultures for $C$. trachomatis at the 21-28 day followup visit was considered to be a microbiologic success or cure. A patient with a positive culture for $C$. trachomatis at the 21-28 day posttreatment visit was considered to be a microbiologic failure. No attempt was made to differentiate relapse from reinfection.

\section{Clinical Response}

Clinical response was assessed based on the resolution of pretreatment signs and symptoms of cervicitis. Disease-related symptoms reported by the patient were dysuria, abnormal vaginal discharge, and abnormal bleeding, while signs assessed by the investigator were mucus color, cervical edema, cervical erythema, and friability of the cervix. Severity was graded by the examiner as mild, moderate, or severe. Clinical response at both follow-up visits was classified as follows:

- cure (resolution of all signs and symptoms)

- improvement (resolution/decrease in severity of some signs and symptoms)

- asymptomatic (no clinical signs or symptoms at pre- or posttreatment visits)

- failure (worsening, no change, or presence of new signs or symptoms)

- indeterminate (evaluation not possible because of missing data)

Participants classified as 'cure' or 'improvement' were considered to be clinical successes.

\section{Patient Populations}

Microbiologically and clinically evaluable patients were defined as follows:

- met the inclusion criteria 
- had a culture for $C$. trachomatis taken 3-8 days posttreatment and were assessed and had a culture taken 21-28 days posttreatment

- took no other antibiotics between initial dosing and follow-up

- missed no more than 1 day of dosing with study drug

- had $C$. trachomatis isolated from pretreatment specimens

\section{Assessment of Adverse Events}

Physical examination of patients was performed, and the patient's body weight, vital signs, and any abnormalities were recorded at the pretreatment visit and at each of the follow-up visits. Clinical laboratory tests were performed on blood and urine samples collected at the pretreatment and 3-8 day

TABLE I. Demographic characteristics of study patients

\begin{tabular}{|c|c|c|c|}
\hline $\begin{array}{l}\text { Patient } \\
\text { characteristic }\end{array}$ & $\begin{array}{l}\text { Grepafloxacin, } \\
400 \mathrm{mg} \\
\text { once daily } \\
(n=228)\end{array}$ & $\begin{array}{c}\text { Doxycycline, } \\
100 \mathrm{mg} \\
\text { twice daily } \\
(n=223)\end{array}$ & $\mathrm{P}$ value* \\
\hline \multicolumn{4}{|l|}{ Age (years) } \\
\hline Mean & 24.5 & 24.7 & 0.75 \\
\hline$S D^{a}$ & 6.0 & 6.9 & \\
\hline Range & $17-49$ & $17-50$ & \\
\hline \multicolumn{4}{|l|}{ Weight $(\mathrm{kg})^{\mathrm{b}}$} \\
\hline Mean & 67.1 & 67.6 & 0.82 \\
\hline SD & 15.5 & 16.2 & \\
\hline Range & $43.2-122.3$ & $41.4-127.3$ & \\
\hline \multicolumn{4}{|l|}{ Race $^{b}$} \\
\hline Black & $|5|(66.5 \%)$ & $146(65.5 \%)$ & 0.22 \\
\hline Caucasian & $47(20.7 \%)$ & $56(25.1 \%)$ & \\
\hline Other & $29(12.8 \%)$ & $21(9.4 \%)$ & \\
\hline \multicolumn{4}{|l|}{ Smoking habits ${ }^{\mathrm{b}}$} \\
\hline Non-smoker & $17 \mid(75.3 \%)$ & $178(79.8 \%)$ & 0.52 \\
\hline Ex-smoker & $6(2.6 \%)$ & $5(2.2 \%)$ & \\
\hline Smoker & $50(22.0 \%)$ & $40(17.9 \%)$ & \\
\hline \multicolumn{4}{|c|}{ Alcohol consumption ${ }^{\mathrm{b}, \mathrm{c}}$} \\
\hline Yes & $32(14.1 \%)$ & $30(13.5 \%)$ & 0.93 \\
\hline No & $195(85.9 \%)$ & $193(86.5 \%)$ & \\
\hline \multicolumn{4}{|c|}{ Caffeine consumption ${ }^{\mathrm{b}, \mathrm{c}}$} \\
\hline Yes & $160(70.5 \%)$ & $167(74.9 \%)$ & 0.23 \\
\hline No & $67(29.5 \%)$ & $56(25.1 \%)$ & \\
\hline \multicolumn{4}{|l|}{ Illicit drug use $e^{b, c}$} \\
\hline Yes & $10(4.4 \%)$ & $15(6.7 \%)$ & 0.30 \\
\hline No & $217(95.6 \%)$ & $207(92.8 \%)$ & \\
\hline Unknown & 0 & I (0.4\%) & \\
\hline
\end{tabular}

*P values were calculated using a linear model with pooled center and treatment as factors for age and weight and using Cochran-MantelHaenszel general association statistic with pooled center as strata for others.

aSD, standard deviation

$\mathrm{b}_{\mathrm{n}}=227$ in the grepafloxacin group.

${ }^{\mathrm{c}}$ Yes = daily or weekly; no $=$ rarely or never.
TABLE 2. Reasons for patient exclusions from microbiologic and clinical efficacy analysis at the 21-28 day follow-up visit

\begin{tabular}{lcc}
$\begin{array}{l}\text { Reason for } \\
\text { exclusion }\end{array}$ & $\begin{array}{c}\text { Grepafloxacin } \\
(\mathrm{n}=146)\end{array}$ & $\begin{array}{c}\text { Doxycycline } \\
(\mathrm{n}=15 \mathrm{I})\end{array}$ \\
\hline $\begin{array}{l}\text { Antibiotic taken between dosing } \\
\quad \text { and end of treatment }\end{array}$ & 0 & 3 \\
Exit evaluation window violation & 46 & 41 \\
General unwillingness/withdrew & & 2 \\
$\quad$ consent & 0 & 4 \\
Unprotected sexual intercourse & 9 & 1 \\
Inclusion criteria not met & 2 & 27 \\
Lost to follow-up & 21 & 109 \\
No positive culture at & & \\
$\quad$ pretreatment & 108 & 4 \\
Less than six doses of study drug & & 7 \\
$\quad$ taken & 5 & 7 \\
Test of cure window violation & 4 & 5 \\
Withdrawal: other reasons & 11 & \\
Withdrawal: positive pretreatment & & 7 \\
$\quad$ gonorrhea culture & &
\end{tabular}

aPatients may have more than one reason for exclusion.

posttreatment visits. The tests were repeated at the 21-28 day posttreatment visit only if clinically indicated.

\section{RESULTS}

Of the 451 patients randomized to the study, 228 patients received grepafloxacin and 223 received doxycycline. Table 1 presents the demographic characteristics for the patient population; the two treatment groups were comparable for the demographic characteristics evaluated.

A total of 112 patients (49\%) receiving grepafloxacin and $104(47 \%)$ receiving doxycycline had pretreatment endocervical cultures positive for $C$. trachomatis. In addition, $U$. urealyticum and $M$. hominis were isolated from 147 (64\%) and 98 (43\%) patients receiving grepafloxacin and $142(64 \%)$ and 92 (41\%) patients receiving doxycycline, respectively.

\section{Microbiologic Response}

Of the 451 patients randomized to the study, 154 patients were evaluable at the 21-28 day posttreatment visit. The reasons for exclusion of the remaining 297 participants are listed in Table 2. Table 3 presents chlamydial eradication rates at the 21-28 day posttreatment visit. C. trachomatis was eradicated in $96.3 \%$ of patients $(78 / 81)$ receiving grepafloxacin and $98.6 \%(72 / 73)$ receiving doxycycline. The $95 \%$ confidence interval for the difference between the two treatments confirmed the 
TABLE 3. Microbiologic response of Chlamydia trachomatis to grepafloxacin and doxycycline at the $21-28$ day posttreatment visit

\begin{tabular}{|c|c|c|c|c|c|}
\hline \multirow[b]{2}{*}{ Assessment } & \multicolumn{2}{|c|}{$\begin{array}{c}\text { Grepafloxacin, } \\
400 \text { mg once daily } \\
(n=81)\end{array}$} & \multicolumn{2}{|c|}{$\begin{array}{c}\text { Doxycycline, } \\
100 \text { mg twice daily } \\
(n=73)\end{array}$} & \multirow[b]{2}{*}{$95 \% \mathrm{Cl}^{\mathrm{a}}$} \\
\hline & $\mathrm{n}$ & $\%$ & $\mathrm{n}$ & $\%$ & \\
\hline Eradication & 78 & 96.3 & 72 & 98.6 & $-9.9 \%, 4.9 \%$ \\
\hline Failure & 3 & 3.7 & 1 & 1.4 & \\
\hline
\end{tabular}

a95\% confidence interval is around the difference of microbiologic success rate (\%); treatment comparison was the response rate of grepafloxacin minus the response rate of doxycycline.

TABLE 4. Clinical response rates at the $2 \mathrm{I}-28$ day posttreatment visit ${ }^{\mathrm{a}}$

\begin{tabular}{|c|c|c|c|c|c|}
\hline & \multicolumn{2}{|c|}{$\begin{array}{c}\text { Grepafloxacin, } \\
400 \text { mg once daily } \\
(n=81)\end{array}$} & \multicolumn{2}{|c|}{$\begin{array}{c}\text { Doxycycline, } \\
\text { I00 mg twice daily } \\
(\mathrm{n}=73)\end{array}$} & \multirow[b]{2}{*}{$95 \% \mathrm{Cl}^{\mathrm{b}}$} \\
\hline & $\mathrm{n}$ & $\%$ & $\mathrm{n}$ & $\%$ & \\
\hline Success & 64 & 88.9 & 51 & 89.5 & $-11.2 \%, 11.7 \%$ \\
\hline cure & 54 & 75.0 & 45 & 78.9 & \\
\hline improvement & 10 & 13.9 & 6 & 10.5 & \\
\hline Failure $^{c}$ & 8 & 11.1 & 6 & 10.5 & \\
\hline Asymptomatic & 9 & & 16 & & \\
\hline
\end{tabular}

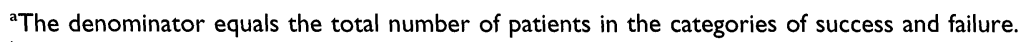

${ }^{b}$ Confidence interval calculated based on a center-weighted method.

'Data missing due to withdrawal for lack of response were mapped to 'failure.'

equivalence of the two study drugs in eradicating this pathogen $(95 \% \mathrm{CI}=-9.9 \%, 4.9 \%, P=0.622)$. The MICs of grepafloxacin and doxycycline for 51 pretreatment $C$. trachomatis isolates were all $\leq 0.25$ $\mu \mathrm{g} / \mathrm{mL}$.

\section{Clinical Response}

Clinical response rates at the 21-28 day posttreatment visit are shown in Table 4. Considering the clinical success rate (cure plus improvement) at this visit, 64/72 patients (88.9\%) receiving grepafloxacin and 51/57 (89.5\%) receiving doxycycline were clinical successes. The $95 \%$ confidence interval for the difference between the two groups confirmed the equivalence of grepafloxacin and doxycycline $(95 \%$ $\mathrm{CI}=-11.2 \%, 11.7 \%)$.

\section{Treatment-Related Adverse Events}

A total of 172 drug-related, treatment-associated adverse events was reported by 107 patients (47\%) in the grepafloxacin group, and 167 such events were reported by 102 patients (46\%) receiving doxycycline (Table 5). Those most commonly ex-
TABLE 5. Most frequently reported drug-related, treatment-associated adverse events during the study ${ }^{\mathrm{a}}$

\begin{tabular}{lcc}
\hline $\begin{array}{l}\text { Body system-adverse } \\
\text { experience }\end{array}$ & $\begin{array}{c}\text { Grepafloxacin } \\
(\mathrm{n}=228)\end{array}$ & $\begin{array}{c}\text { Doxycycline } \\
(\mathrm{n}=223)\end{array}$ \\
\hline $\begin{array}{l}\text { Body as a whole } \\
\text { abdominal pain } \\
\text { headache } \\
\text { infection }\end{array}$ & $6(2.6 \%)$ & $5(2.2 \%)$ \\
$\begin{array}{l}\text { Digestive } \\
\text { diarrhea } \\
\text { nausea } \\
\text { vomiting }\end{array}$ & $\begin{array}{c}11(1.8 \%) \\
13(5.8 \%)\end{array}$ & $3(1.3 \%)$ \\
$\begin{array}{l}\text { Nervous } \\
\text { dizziness }\end{array}$ & $9(3.9 \%)$ & $4(1.8 \%)$ \\
$\begin{array}{l}\text { Skin and appendages } \\
\text { pruritus }\end{array}$ & $37(16.2 \%)$ & $34(15.2 \%)$ \\
$\begin{array}{l}\text { Special senses } \\
\text { taste perversion }\end{array}$ & $5(2.2 \%)$ & $20(9.0 \%)$ \\
$\begin{array}{l}\text { Urogenital } \\
\text { leukorrhea } \\
\text { vaginitis }\end{array}$ & $8(3.5 \%)$ & $5(2.2 \%)$ \\
At least one drug-related & $6(2.6 \%)$ & $7(3.1 \%)$ \\
adverse event & $35(15.4 \%)$ & $1(0.4 \%)$ \\
\hline
\end{tabular}

aDrug-related $=$ possible, probable, or unknown relationship to study drug. 
perienced in the grepafloxacin group were nausea $(16 \%)$, taste perversion (15\%), and vaginitis $(6 \%)$, and in the doxycycline group the most common drug-related events were nausea $(15 \%)$, vaginitis (9\%), and vomiting (9\%). The incidences of headache and vomiting were statistically significantly higher in the doxycycline group: headachegrepafloxacin $1.8 \%$, doxycycline $5.8 \%, P=0.026$; vomiting-grepafloxacin $2.2 \%$, doxycycline $9.0 \%$, $P=0.002$. The incidence of taste perversion was statistically significantly higher in the grepafloxacin group $(15.4 \%$ vs. $0.4 \%, P<0.001)$. No serious treatment-associated adverse events were reported, and there were no deaths.

Three patients in each treatment group were withdrawn because of adverse events. In five of these patients the events were judged to be related to study drug (grepafloxacin group: taste perversion, nausea, mild rash, dyspepsia, dizziness; doxycycline group: dyspepsia, abdominal pain, nausea/ vomiting, chest pain, dyspnea).

\section{Clinical and Laboratory Tests}

There were no clinically significant trends or changes in body weight, vital signs or clinical laboratory data that were indicative of study drug toxicity. Small changes in hematologic parameters, within the normal range for both treatment groups, were seen at both follow-up visits. Only isolated cases of clinically significant serum chemistry abnormalities were detected.

\section{DISCUSSION}

Because of the insidious nature of chlamydial infection and its potentially serious sequelae in infected women and their infants, prompt and effective antimicrobial therapy is imperative. In addition to treating women with symptoms, however, we must also improve patient identification to recognize the far greater number of asymptomatic individuals who also require antimicrobial therapy. Strategies that may be employed include routine testing of high-risk women, testing as part of infertility investigations, and screening in women using oral contraceptives prior to abortion and following miscarriage and premature birth. ${ }^{6}$ In order to avoid the serious sequelae of $C$. trachomatis, compliance with treatment is essential; evidence suggests that compliance is likely to be better with once-daily than with twice-daily regimens. ${ }^{16}$ Compliance within clinical practice is likely to be less than that observed during a clinical trial.

The primary aim of this study was to compare the microbiologic and clinical efficacies of a 7-day treatment with once-daily grepafloxacin and twicedaily doxycycline in women with $C$. trachomatis endocervical infections. The overall microbiologic and clinical success rates for the two study drugs were statistically equivalent. C. trachomatis was eradicated in more than $96 \%$ of cases in both treatment groups at both posttreatment visits. Both treatment regimens were well tolerated, and no unique or unexpected laboratory findings were seen.

In summary, a 7-day, once-daily treatment with grepafloxacin was as effective as a 7-day, twicedaily treatment with doxycycline. Grepafloxacin's activity against $N$. gonorrhoeae may expand its utility to patients with gonorrhea, for whom antimicrobial treatment for chlamydial infection is also recommended because of the high incidence of coinfection. It may, therefore, provide a useful alternative for the treatment of sexually transmitted endocervical infections.

\section{ACKNOWLEDGMENTS}

Participating Centers: Eastern STD Clinic, Baltimore, MD (Dr. Anne Rompalo); Jefferson County Health Department STD Clinic \& University of Alabama at Birmingham, Birmingham, AL (Dr. Edward W. Hook III); Boston City Hospital STD Clinic, Boston, MA (Dr. Brant Viner); SUNY Health Science Center \& Crown Heights STD Clinic, Brooklyn, NY (Dr. William M. McCormack); Municipal STD Clinic, Chicago, IL (Dr. Romina Kee); Denver Disease Control, Denver, CO (Dr. John M. Douglas Jr.); University of Texas Medical Branch, Galveston, TX (Dr. Garland Anderson); Bell Flower Clinic, Indianapolis, IN (Dr. Robert B. Jones); Louisiana State University, New Orleans, LA (Dr. David H. Martin); Central Florida Medical Research Center \& UCF Student Health Services, Orlando, FL (Dr. Abdollah Iravani); Wake County Health Department, Raleigh, NG (Dr. Peter Leone); Weber-Morgan District Health Department Clinic, Ogden, UT (Dr. Manford Gooch III); University of Louisville Department of Obstetrics/Gynecology, Louisville, KY (Dr. Marcello Pietrantoni); City and County of San Francisco Department of Public Health, San Fran- 
cisco, CA (Dr. Sharon Safrin); Future Health Care Research Center, California State University \& Cal Poly State University, Fresno, CA (Dr. James McCarthy); Westover Height Clinic, Portland, OR (Dr. Rosalee Movious); Future HealthCare Research Centers at Alabaster and Birmingham, AL (Dr. Sam Roberts).

\section{REFERENCES}

1. Centers for Disease Control and Prevention: Recommendations for the prevention and management of Chlamydia trachomatis infections, 1993. MMWR 42(RR12): 1-39, 1993.

2. Washington AE, Johnson RE, Sanders LL: Incidence of Chlamydia trachomatis infections in the United States: using reported Neisseria gonorrhoeae as a surrogate. In: Oriel D, Ridgway G, Schachter J, et al. (eds): Chlamydial Infections. Cambridge: Cambridge University Press, pp 487-490, 1986.

3. Kassler WJ, Cates W Jr: The epidemiology and prevention of sexually transmitted diseases. Urol Clin North Am 19:1-12, 1992.

4. Diseases due to chlamydia. Sci Am Med 7:1-18, 1994.

5. Brunham RC, Maclean IW, Binns B, et al.: Chlamydia trachomatis: its role in tubal infertility. J Infect Dis 152: 1275-1282, 1985.

6. Tuormaa TE: Adverse effects of genito-urinary infections with particular reference to fertility and preconceptional care. J Nutr Med 4:351-361, 1994.

7. Schachter J: Chlamydial infections (parts 1, 2 and 3). N Engl J Med 298:428-435, 490-495, 540-549, 1978.

8. Bell TA, Stamm WE, Wang SP, Kuo CC, Holmes KK, Grayston JT: Chronic Chlamydia trachomatis infections in infants. JAMA 267:400-402, 1992.
9. Zenilman JM, Neumann T, Reichart C: Antibacterial activities of OPC-17116, ofloxacin, and ciprofloxacin against 200 isolates of Neisseria gonorrhoeae. Antimicrob Agents Chemother 37:2244-2246, 1993.

10. Kenny GE, Cartwright FD: Susceptibilities of Mycoplasma hominis, Mycoplasma pneumoniae, and Ureaplasma urealyticum to a new quinolone, OPC-17116. Antimicrob Agents Chemother 37:1726-1727, 1993.

11. Roblin PM, Montablon G, Hammerschlag MR: In vitro activities of OPG-17116, a new quinolone; ofloxacin; and sparfloxacin against Chlamydia pneumoniae. Antimicrob Agents Chemother 38:1402-1403, 1994.

12. Martin DH, Mroczkowski TF, Paliaro C: In vitro activity of OPC-17116, ofloxacin and doxycycline versus recent clinical isolates of $G$. trachomatis. 34th Interscience Conference on Antimicrobial Agents and Chemotherapy, 1994. Abstract D75.

13. Ridgway GL, Salman H, Robbins MJ, Dencer C, Felmingham D: The in vitro activity of grepafloxacin against Chlamydia spp., Mycoplasma spp., Ureaplasma urealyticum and Legionella spp. J Antimicrob Chemother 1998 (in press)

14. Matsuda $S$ and The Japanese Collaborative Study Group OPC-17116 in Gynaecology: Clinical experience with OPC-17116 in the treatment of gynaecological infections and its penetration into gynaecological tissues. Drugs 49(Suppl. 2):395-398, 1995.

15. Taira K, Koga H, Kohno S: Accumulation of a newly developed fluoroquinolone, OPC-17116, by human polymorphonuclear leukocytes. Antimicrob Agents Chemother 37:1877-1881, 1993.

16. Eisen SA, Miller, DK, Woodward RS, et al.: The effect of prescribed daily dose frequency on patient medication compliance. Arch Intern Med 150:1881-1884, 1990. 


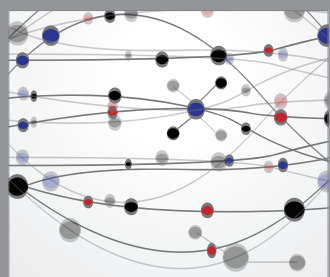

The Scientific World Journal
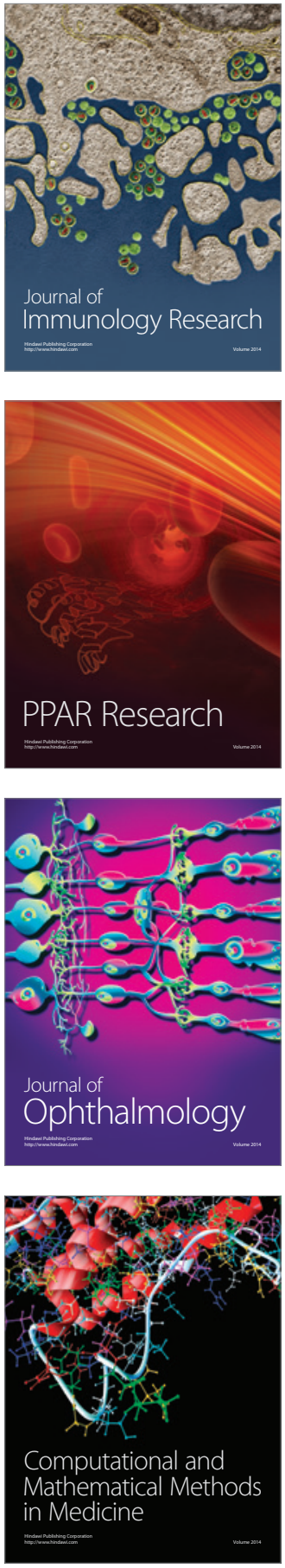

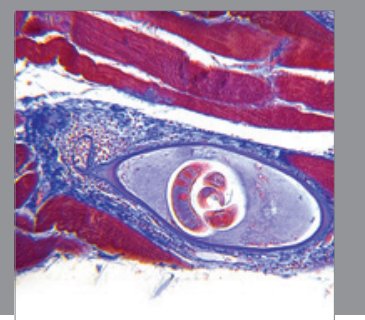

Gastroenterology

Research and Practice
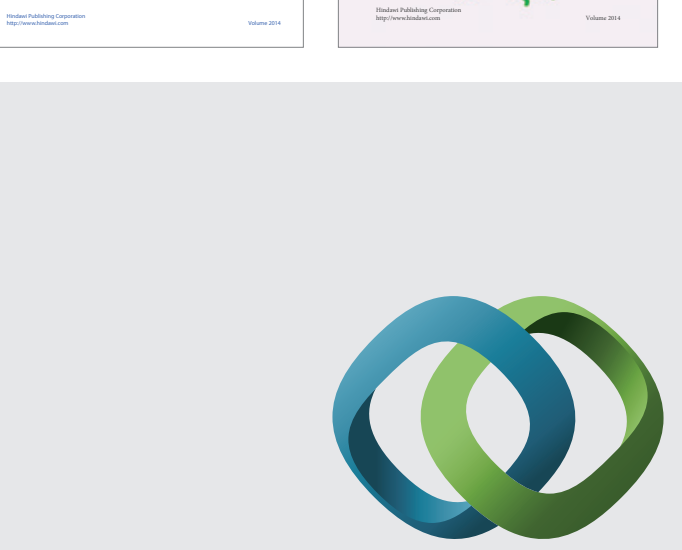

\section{Hindawi}

Submit your manuscripts at

http://www.hindawi.com
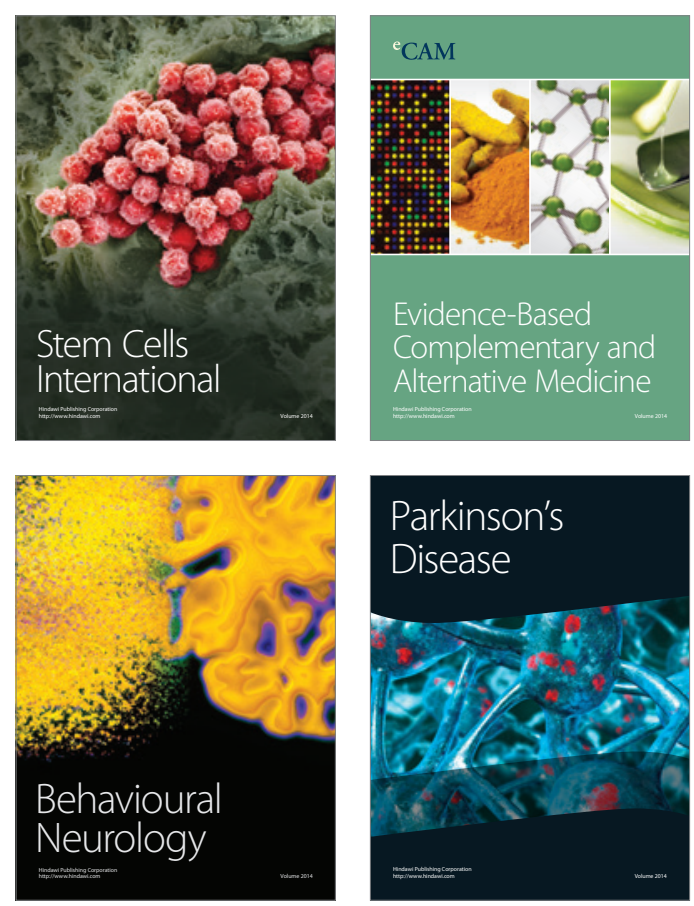

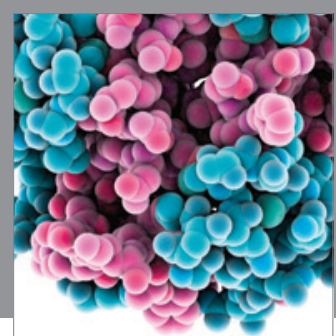

Journal of
Diabetes Research

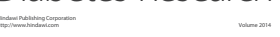

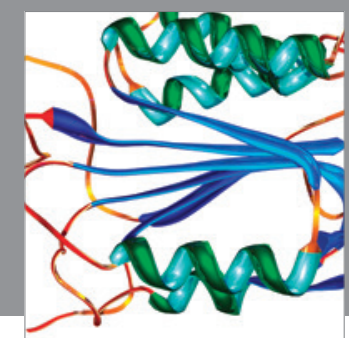

Disease Markers
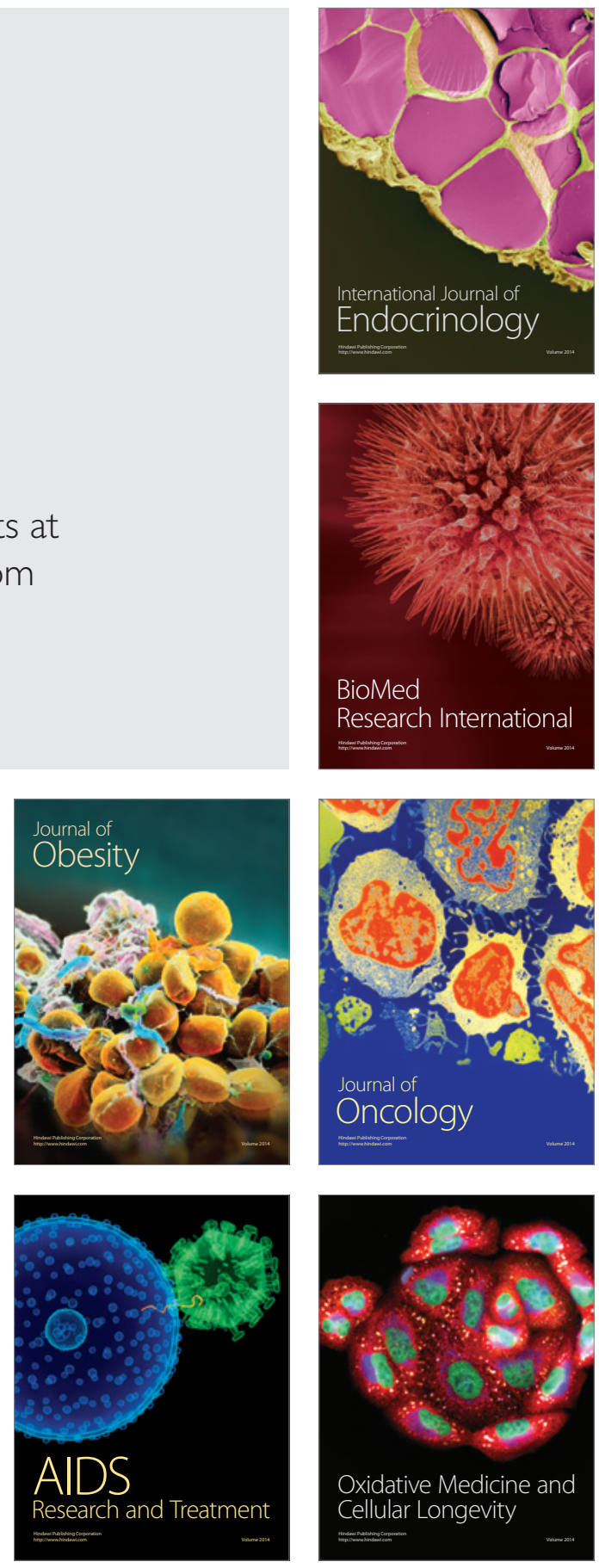